\title{
Continuing professional education in engineering faculties: Transversal integration of Sustainable Human Development in basic engineering sciences courses
}

\author{
Agustí Pérez-Foguet ${ }^{1}$, Boris Lazzarini ${ }^{2}$ \\ ${ }^{1}$ Universitat Politècnica de Catalunya, School of Civil Engineering, Department of Civil and Environmental \\ Engineering, Research Institute for Sustainability Science and Technology, Engineering Sciences and Global \\ Development Research Group, c/ Jordi Girona 1-3, C2 310,08034 Barcelona, Spain, agusti.perez@upc.edu \\ ${ }^{2}$ Universitat Politècnica de Catalunya, Research Institute for Sustainability Science and Technology, \\ Engineering Sciences and Global Development Research Group, c/ Jordi Girona 1-3, Ed. K2M, 08034 \\ Barcelona, Spain, boris.lazzarini@upc.edu
}

The integration of sustainable development in higher education is increasingly recognised as a priority for a growing number of universities. Nonetheless, numerous barriers for change remain and particular attention should be given to the success factors fostering an effective integration. The present contribution analyses the extent to which a professional development programme, aimed at engaging and empowering faculty, has positive effects at integrating sustainable human development principles into existing courses of engineering; specifically, in new teaching modules in a subject of basic engineering science, implemented in regular courses of the first year of an engineering degree programme. The methodology includes: i) a focus group conducted with the students of the engineering courses involved in the initiative; and ii) two in-depth interviews conducted with the academic coordinator of the subject analysed. The results of the present case study highlight the relevance of professional development programmes addressed to academics in terms of students' positive perception of the teaching innovation proposal and the empowerment of the academics involved in the training. The findings also suggest that specific university cultures and values, as well as barriers and resistance of academics to innovative processes, may contribute to frustrating the efforts of motivated professors. The conclusions emphasise the potential of continuous professional development initiatives addressed to small groups of professors, especially if reinforced with appropriate incentives and active institutional support.

Keywords: Engineering, Sustainable Human Development, Continuing Professional Development, Higher Education Policy. 


\section{Introduction}

Engineering is recognised as a critical discipline for addressing sustainable development (SD) challenges (Davidson et al., 2010; Karatzoglou, 2013). Engineers-in-training will be future leaders and specialised professionals who will hold important positions in economic and political spheres. In both cases, they will play a critical role in the promotion of a more sustainable future, bearing the responsibility of making important decisions that have a wide impact on the social, economic and environmental domains. For this reason, there have been many calls in the last decades for a renovation of engineering competencies and a change in curricula and pedagogies integrating SD concepts and principles (Boni and Pérez-Foguet, 2008; Lozano and Lozano, 2014; Mulder et al., 2015; Segalàs et al., 2009). A number of technical faculties and universities have been reconsidering the content of their curricula and adopting diverse strategies (Lozano and Lozano, 2014; Rose et al., 2015; von Blottnitz et al., 2015), but further efforts are needed in order to properly integrate SD in teaching contents and pedagogies. The transformation in learning in education for sustainability requires the commitment of faculty and the engagement of students (Leal Filho et al., 2018). Faculty members can be considered as the foremost contributors to curriculum renewal (Barth and Rieckmann, 2012). For this reason, building capacity of academics towards SD is critical to fostering the transformation of learning and training environments (Cebrián et al., 2015; Sammalisto et al., 2015).

Scientific literature reports different experiences of capacity building of academics in SD, specifically focused on technical universities such as 'educate the educators' approaches aimed at integrating SD into regular courses (Barth and Rieckmann, 2012; Ceulemans and De Prins, 2010; Lozano García et al., 2008; Pérez-Foguet et al., 2018), or aimed at the development of new degrees (Lozano and Lozano, 2014). Other approaches, rather than focusing on the process of 'training' academics, are specifically aimed at fostering their personal contributions to SD, namely by promoting reflection on how to help integrate SD in regular subjects based on their expertise and disciplines (Holmberg et al., 2008; Svanström et al., 2012). Among the different approaches indicated to promote the integration of SD in curricular activities (Watson et al., 2013), intertwining SD as a concept within regular courses has been described as the most favourable approach for integrating SD (Lozano and Lozano, 2014), providing suitable chances to incorporate into professional practices the SD principles (Rose et al., 2015).

Specific initiatives have focused first and foremost on the integration of sustainable human development (SHD) in engineering curricula (Boni and Pérez-Foguet, 2008, 2006; Pérez-Foguet et al., 2005). SHD has been defined as "the expansion of the substantive freedoms of people today while making reasonable efforts to avoid seriously compromising those of future generations" (UNDP, 2011). The concepts of SD and SHD do not present precise theoretical boundaries and are subjected 
to different interpretations (Absell, 2015). Specifically, in this contribution the concept of SHD is employed when emphasising the fulfilment of basic needs and the expansion of human capabilities within SD approaches.

Engineering approaches to teaching and learning are characterised by technical paradigms and a strong disciplinarity (Halbe et al., 2015). Consequently, it is particularly challenging to integrate the principles of inter-, multi- and transdisciplinarity characterising SD. Recently, Lazzarini et al. (2018) and Lazzarini and Pérez-Foguet (2018) have analysed the characteristics respectively of the academic and research profiles of engineering faculty involved in continuing professional development (CPD) programmes aimed at fostering the integration of SD in regular courses. The results showed a strong interdisciplinary profile of the faculty involved, as well as a general commitment towards the integration of SD principles in their different academic functions and its promotion outside the university. However, these engaged academics are far from representing the typical profile of an engineering professor. Academic engagement towards SD is especially difficult for those disciplines included in 'formal sciences', such as mathematics, logics and statistics, which are characterised by abstract structures and languages. It would be especially important that students start their training in integrating sustainability principles from the very beginning, yet these formal science disciplines are commonly taught in the first year of engineering degrees. For professors of formal science disciplines, it is particularly challenging to include SD into their teaching, and CPD programmes are especially useful to provide them with pedagogical and practical resources to be used in their teaching practices. The current literature offers very limited research that focuses on educating the educators for interconnecting formal science disciplines and SD, and specifically for evaluating the impact of specific training programmes addressed to academics.

In light of these challenges, this contribution aims to describe a CPD programme on SD focused on the engineering faculty, assessing the degree to which such programme has positive/desired effect on both academics and students, and especially focusing on formal science disciplines. Specifically, the research focuses on the effects of integrating SD into new teaching modules in a subject of basic engineering science, which was implemented in regular courses of the first year of engineering degrees. The specific objectives of this study are to determine:

- the students' perception of the subject analysed in the present case study;

- the academic coordinator's perception of the subject incorporating SD concepts.

This contribution seeks to explore these research objectives by analysing a case study of professional development of academics - focused on a single cohort of students, with a single instructor specifically oriented on basic engineering science courses, in the framework of a continuing professional education programme addressed at engineering faculty implemented at the Universitat Politècnica de Catalunya, Barcelona, Spain (UPC). 
To accomplish this task, methods include: i) a focus group that analysed students’ perception about their learning experience; and iii) two in-depth interviews, specifically aimed at exploring learning acquisition and factors related to motivation of academics involved in the training.

\section{The professional development programme and incentives for faculty}

The present contribution focuses on a CPD programme aimed at engaging and empowering faculty of the UPC to integrate SD concepts into their existing courses. This 2-year initiative, which started in 2016, was funded by the Barcelona City Council and involved different profiles of engineering faculty, from academics with little-to-no previous experience in SD to professors who already integrate SD into their academic functions. In total, 15 professors from different engineering areas participated in the professional development programme; all of them joined the programme voluntarily. Faculty members have been engaged through diverse training activities aimed at improving the competencies and attitudes of academic staff towards sustainability, such as periodical workshops that engage all trainees, and individual coaching sessions. Furthermore, the training approach promoted the development of case studies dealing with SD issues that are relevant to a local scale, as an effective way to increase the perceived relevance of basic sciences courses within engineering studies, and to complement traditional approximations that focus mainly on technology courses. The final goal of the programme was to engage faculty in proposing and developing teaching contributions to SD based on their own disciplines and expertise and to apply these to real-world teaching situations, ideally in regular courses.

The methodological approach driving this professional development initiative was founded on previous relevant experiences of faculty capacity building promoted in technical universities across Europe. The European initiative Global Dimension in Engineering Education (GDEE, 2015a), coordinated by the authors, was developed with the aim of mainstreaming SHD in engineering education, and specifically for improving the competences of faculty of engineering universities to effectively integrate SHD as a crosscutting issue in teaching activities. Additionally, the meaningful training experiences promoted by Svanström et al. (2012) at the Chalmers University of Technology (Sweden) and Peet et al. (2004), at the Delft University of Technology (The Netherlands), were taken into account. In both cases, the main focus of the CPD initiatives is to explore how lecturers can contribute to SD from their own disciplines with an open approach, rather than training academics in a rigid and traditional manner on how they should incorporate sustainability concepts. Following these two initiatives, the training programme presented here specifically combined workshop sessions, including training and discussion activities, with individual coaching sessions. The purpose of this method was two-fold. First, workshops aimed to foster discussion on relevant topics related to embedding SD into engineering courses, finding common grounds between respective disciplines and 
contents related to SD. In addition to the specific contents related to SD, workshops included discussions on active learning pedagogies, competencies articulation and outcomes assessment, and successful experiences, among other issues. Furthermore, one of the purposes of the workshop activities was to foster a supportive learning environment and group engagement, giving participants the possibility to share personal experiences and to discuss relevant sustainability topics and how they can be reflected in respective courses. Second, individual coaching sessions were held that aimed at increasing engagement and motivation of professors for embedding SD into real-world teaching modules and subjects. Academics were provided numerous type of support, such as for the process of exploring potential topics to be included into their regular subjects, determining the most appropriate pedagogies and assessing students.

\subsection{Incentives for academics}

The participation in professional training and potential engagement in teaching activities offered within the CPD initiative presented diverse incentives for the academic participants, which are briefly described below. Note that in Spain, the incentives related with teaching performance of academics are more dependent on the faculty promotion/evaluation rules of each university; in contrast, the incentives linked with research and technology transfer results are more uniform and, in general terms, are more likely to follow international accepted standards.

Teaching innovation: the participation in teaching innovation training programmes, as well as the development of teaching innovation materials are both a prominent part of the evaluation of academics. The evaluation process of these teaching merits includes, specifically, a self-evaluation form presented by the academic; this self-evaluation needs to be accompanied by the respective evidence, which are qualitatively analysed by a specific competent commission.

Student satisfaction surveys: Standardised surveys addressed to students (which were traditionally paper-based but now are usually online questionnaires) also are an essential point of academic evaluation. Teaching innovation initiatives, particularly those related to SD and development cooperation could be well received by students; consequently, this can contribute to higher rates in student satisfaction surveys.

Engagement in development cooperation projects: The academic initiatives focusing on countries in the global south are considered strategically relevant for their contribution to capacity building, as well as for their innovation features, for both professors and students. Thus, having engaged in teaching projects or training practices related to development cooperation, or having participated in awareness raising activities and development education, is considered an added value in the evaluation process. 
Conference papers/contributions: Depending on their academic recognition, conference contributions can be considered (with more or less weight) in the evaluation of academic performance. Notably, the professional development initiative in this research actively promoted the participation to national/international conferences that focused on teaching innovation, by financing attendant expenses (registration fees, travel expenses). Furthermore, participating professors were offered a personalised follow-up aimed at the development and improvement of conference papers/contributions specifically focused on teaching innovation.

Scientific publications, research projects and knowledge transfer contracts: In some cases, the aforementioned incentives can contribute to the development of scientific publications, research projects or knowledge transfer contracts, which are especially well rated in the process of academic evaluation, in concordance with international standards.

\section{Methods}

\subsection{The case of Lineal Algebra}

Lineal Algebra is a compulsory teaching unit of the Technical School of Industrial Engineering of Barcelona (ETSEIB) of the UPC and is given during the first year of different engineering degrees programmes. Enrolled students traditionally come from three engineering areas: material engineering, industrial technologies engineering and chemical engineering. On average, 500 students take the subject each semester; they are divided into 10 groups, each one with an assigned professor, with the general supervision of an academic coordinator. The coordinator must ensure compliance of the specific teaching and assessment criteria of the subject, which is set in the curriculum approved by the faculty board and should be used by all professors teaching the subject to the different groups.

In the framework of the CPD programme, a professor of the UPC proposed to embed elements of SD into a regular subject of Lineal Algebra - of which she was the academic coordinator - using a new teaching project focused on the 'long-term viability of a possible construction of a dam'. Specifically, a decision was made to integrate and assess UPC transversal competence 'sustainability and social commitment' (SSC), with the approval of the programme board.

Transversal competences are common to all UPC degrees, and are specifically: entrepreneurship and innovation; sustainability and social commitment; a foreign language; effective oral and written communication; teamwork; effective use of information resources; and autonomous learning. These competences are opportunely integrated into the curricula, in terms of disciplinary matters, according to specific criteria approved by the boards of the different study programmes. In practice, this means that transversal competences might be differently integrated into the curricula of the distinct engineering areas, as can be seen in Table 1. Additionally, two schools of the UPC (ETSEIAT and 
ETSEIB), based in different Catalan cities, offer the same engineering degree integrating SSC competence in different disciplinary matters. Currently, only the curriculum of the degree in material engineering integrates SSC competence in the disciplinary matter of mathematics.

Table 1. Integration of the transversal competence SSC in specific disciplinary matters of the different degrees programmes.

\begin{tabular}{|c|c|c|c|}
\hline \multicolumn{2}{|c|}{ Industrial Technology Engineering } & Chemical Engineering & Material Engineering \\
\hline \multicolumn{4}{|c|}{ ETSEIAT $\quad$ ETSEIB } \\
\hline Chemistry & & Chemistry & Mathematics \\
\hline $\begin{array}{l}\text { Environmental } \\
\text { technology and } \\
\text { sustainability }\end{array}$ & $\begin{array}{l}\text { Environmental } \\
\text { technology and } \\
\text { sustainability }\end{array}$ & $\begin{array}{l}\text { Environmental } \\
\text { technology and } \\
\text { sustainability }\end{array}$ & $\begin{array}{l}\text { Environmental } \\
\text { technology and } \\
\text { sustainability }\end{array}$ \\
\hline $\begin{array}{l}\text { Mechanical } \\
\text { engineering and } \\
\text { materials }\end{array}$ & Project methodology & Project methodology & Project methodology \\
\hline Bachelor's thesis & $\begin{array}{l}\text { Economy and } \\
\text { Enterprise }\end{array}$ & $\begin{array}{l}\text { Economy and } \\
\text { Enterprise }\end{array}$ & $\begin{array}{l}\text { Elective subjects (e.g. } \\
\text { Climate change: } \\
\text { Science, Energy, } \\
\text { Economics, Politics and } \\
\text { the future) }\end{array}$ \\
\hline \multicolumn{3}{|c|}{\begin{tabular}{l|l} 
Organisation of \\
production
\end{tabular}} & \\
\hline & & Bachelor's thesis & \\
\hline
\end{tabular}

Adoption of a specific curriculum for each degree programme follows a regulated process of approval and monitoring that involves the Spanish Ministry of Education and autonomous regions (in this particular case, Catalonia). The curriculum defines specific subjects, which are grouped in blocks of disciplinary matters, including specific and transversal competences. Teaching guides of the different subjects are commonly updated each year. Any potential changes must always be adjusted according to the curriculum that has been legally approved and must be validated by the board or the respective programmes.

SSC transversal competence was integrated into the UPC studies as a result of a participatory process aimed at promoting sustainability in the different functions of the university, which was stimulated by committed faculty and supported by the management board in charge at that time (Leal Filho et al., 2018; Pérez-Foguet and Cruz López, 2011). SSC specifically requires the acquisition of: i) knowledge and understanding of the complexity of the welfare society economic and social phenomena; ii) the capacity to relate well-being to globalization and sustainability; and iii) the ability to use technology, economics and sustainability in a balanced and compatible way (Pérez-Foguet and Cruz López, 
2011). This competence can be acquired progressively over three levels, typically through different subjects in the curricula, which are defined as follows:

1. Analyse the global context systematically and critically; address sustainability and social commitment in an interdisciplinary manner; and recognize social and environmental implications of the engineering professional activity.

2. Apply sustainability criteria and professional deontological codes to the design and evaluation of technological solutions.

3. Carry out projects and professional activities consistent with human development, sustainability and social commitment, taking into account social, economic and environmental dimensions in the identification of the problems.

The subject of Lineal Algebra was specifically selected for introducing elements of SD, with the aim of promoting students to reflect on the global sustainability challenges as well as on the social and environmental implications of engineering. As this is a first-year course, the SSC competences were mainly focused from the first level described above. The pedagogical approach of the teaching project was based on Project Based Learning (PBL) including aspects of collaborative learning. In PBL - an approach particularly suitable for integrating SD into the engineering curriculum (Lehmann et al., 2008) - students are provided with complex real-life situation problems as well as with guidelines on how to solve them. The participants' learning processes are enriched through the analysis of the different approaches and perspectives applied to solve the problems. This methodology enables different competencies to be approached in a collaborative way, allowing students to understand environmental and societal problems as a whole (De Graaff and Kolmos, 2006). Students' results and learning outcomes had to be organised and displayed through public e-portfolios, in order to promote self-reflection on achieved results and discussion among students, which has been shown to ensure a more meaningful learning experience (Chen et al., 2018).

The students had to work in small groups on the project "Long-term effectiveness of a potential construction of a dam”, which has been described extensively elsewhere (EScGD, 2018; GarciaPlanas and Taberna, 2017). In brief, the activity was designed to propose the possibility to build a dam to regulate the basin of one of the contributing rivers, with the objective of satisfying the needs of water for irrigation. Students were provided with the maximum capacity of the dam, the amount of water required for irrigation and the amount that should be left to maintain the water quality standards for other uses, provided that the water level of the dam plus the weekly contribution of water from the river does not reach a minimum preventing the provision of water. Using linear algebra, students were required to assess the viability of the irrigation strategy analysing the temporal evolution of the reservoir water balance under the given conditions as well as considering any possible influence that climate change effects would have on it. In addition, students were asked to assess the social benefit 
of the dam by counterbalancing the benefits obtained by the irrigation versus potential social conflicts caused by land expropriations and consequent displacement of the inhabitants of such area. Finally, they carried out discussions in small groups, with the objective of reaching a consensus about agreeing or disagreeing with the proposal to build the dam.

\subsection{Data collection}

The faculty training initiative combined traditional training sessions, such as group lectures and workshops, with personal coaching sessions that aimed at promoting the integration of SD principles into teaching practices and were based on the academic experience and interests of each trainee. The decision of analysing a small case study, specifically focused on a single cohort of students and a single professor, was motivated by the need to collect and deepen detailed information on personal thoughts, feelings and perceptions of all the actors involved, in order to better assess the customised training proposal. A mixed approach was used to collect data for the research. First, a focus group was conducted with students in the linear algebra course. Second, two semi-structured interviews of the professor in the CPD programme that promoted the teaching initiative.

\subsubsection{Focus group}

The focus group is a qualitative research method aimed at obtaining, usually from small groups of people, the perceptions, attitudes and opinions of the participants about a specific area of interest (Krueger, 2015). An informal, interactive and non-threating environment encourages an open group discussion, providing the opportunity to deepen specific topics (Sharma et al., 2017). In this research, a focus group was specifically employed to get detailed perceptions of students about a learning experience promoted in the framework of the professional development programme of academics. Eight student volunteers participated in the focus group: four men and four women. A call for participation was made among all students who passed the subject. The group facilitator (one of the authors) did not know the number of students participating, their gender or their identity until the start of the group activity. The focus group was held after completing the subject's exams, at the end of the semester. Data were transcribed verbatim and subsequently reviewed by two independent researchers.

The focus group was aimed at assessing the overall perception of students on the subject of Lineal Algebra described earlier, and specifically focused at assessing the following issues:

Organisation and approach of teaching proposal 
- Organisation of the subject (modules, activities, assessment)

- Novelty and impact of the pedagogical approach

- Relevance of the learning experience (in connection with previous experience and/or future expectations).

Contents of the teaching proposal

- Relevant issues studied/discussed

- Issues that should have been deepened

Individual competencies acquired as citizens and future engineers

- Cognitive: relevant knowledge, concepts

- Non-cognitive: empathy, solidarity, compassion, intercultural sensitivity

- Professional: team work, innovation, multidisciplinary work

\subsubsection{Semi-structured interviews}

The qualitative interview is a research tool with the aim of identifying the personal vision of the interviewees in relation to a specific topic through their way of capturing the complexity of a given situation using their own perceptions and experiences, as well as with their own words and terminology (Patton, 2015). The semi-structured interview, starting from a guide comprising the main issues that have to be deepened, is flexible so that both the respondent and the interviewer can decide which topics should be discussed in detail.

Based on previous relevant experiences (Brockhaus et al., 2017), a guide to be used for interviews was developed to guarantee consistency; this was later validated by a panel of experts, after including suggested modifications, according to Charmaz (2006). Two interviews were conducted with the academic coordinator of the subject of Lineal Algebra; the second one after approximately one year from the end of the training initiative, in order to assess the continuity of the intervention. The interviews were both conducted on site and lasted approximately one hour. They were recorded, transcribed verbatim, and then analysed by two different researchers.

Following the research of (Barth and Rieckmann, 2012), the first interview was aimed at exploring diverse issues related to the professional development initiative:

Individual competencies: increased knowledge, competencies and skills related to SD:

- $\quad$ Cognitive: knowledge, concepts, relations.

- $\quad$ Non-cognitive: awareness, motivation, values. 
- $\quad$ Professional: knowledge of different teaching strategies and methods.

Issues related to the professional development of academics: the research aimed at identifying changes in the teaching routine, and specifically if the professor attempted appropriate/innovative pedagogical approaches in the classroom. In addition to the ability and motivation of each participant as a result of the training activity, interviews were aimed at exploring, within this framework, specific factors that favour or limit the changes in teaching practices, such as:

- $\quad$ Student expectations

- $\quad$ Curriculum requirements

- $\quad$ Time investment of academics

- $\quad$ External factors (coaching, availability of teaching resources, other external support)

Potential impact within the organization: beyond the changes strictly related to the teaching function of academics, another important aspect to consider is the potential involvement of teachers in disseminating and promoting SD principles in their university organization. Possible contributions in this regard may have different levels of involvement, from the personal to the institutional sphere:

- $\quad$ Dissemination of professional activities to colleagues

- $\quad$ Promotion of changes in curricula

- $\quad$ Encouraging political / institutional strategies for promoting SD

The second interview was purposefully less structured than the first one, and specifically aimed at exploring to which extent the professor continued to integrate SD aspects into her teaching activities, at one year after the end of the professional development training. Additionally, attitudes and motivation towards SD were planned to be assessed, as well as any problems or barriers that might have been encountered during this time.

\section{Results and Discussion}

\subsection{Focus group with the students of Lineal Algebra}

The results of the focus group conducted with the students of linear algebra are presented and discussed in this section.

Overall, students showed a very good acceptance of the active learning pedagogies employed and of the topics integrated into the subject. Students initially minimised the importance, in the context of the subject, of those embedded topics related to water use and socio-environmental aspects; rather, they focused primarily on issues related to the mathematical resolution of the problems raised in the case 
study. It is probably that mathematical aspects were generally perceived to be the most important factors.

"The subject assessment was in mathematics; the sustainability part came from the mathematical problem. You had to draw the conclusions... I mean, at the social level, but what it was assessed and the most important and difficult issue was the mathematical problem."

Subsequently, during the group discussion, student perceptions gradually began to emerge that were more related to the specificity of the problems studied, as well as to personal considerations about the potential applications in the real world of an abstract matter such as linear algebra. Furthermore, more general aspects related to the professional role of engineering came into the discussion.

"I didn't think that linear algebra could have such a direct application .... Right now, I like to see that what I am doing is useful and that they are not just numbers but can also have a social application. This is quite different from the other subjects..."

"It has a real application after all... from what we have seen so far, this is the only subject that has some application to our future as engineers. Besides that, algebra is a subject that, when you first see it, you say ...well, what is it for? Any initiative like this one is welcome".

Despite the markedly mathematical nature of the subject, it can be noted that the content and teaching methodology favoured important reflections of the students, which came up from group dynamics and discussions on various topics raised in the subject, addressing both mathematical and environmental/social issues related to the sustainability of a dam. The students, who had been divided into small groups of five people, had to find an agreement for the solution of a problem with different variables, keeping in mind to include: i) mathematical elements (balance/water efficiency of a dam); ii) environmental factors (water as a natural resource, ensuring sufficient water supply for irrigation, effects of climate change); and iii) social factors (e.g., the possibility that residents would be required to move to other areas, with consequent social tensions). The requirement that the group find a mutually agreed-upon solution for the possible construction of the dam stimulated discussion and comparison of different points of view and perceived priorities on sustainability issues. It is worth highlighting that this was the only subject of the first year of the degree on which students worked mainly in a group.

"Working in a group, we were forced to debate about what we were going to decide [about the dam construction], and you can't agree with every one of the group. So we had to debate about water problems in order to find a solution. This has been very different from the others [subjects]. Even though I knew that engineering has a lot of applications, but to see an example so clearly like that in the first year...., well, I liked it.” 
This confirms that these group activities can be an effective way to promote interactions with people with different views and paradigms (Halbe et al., 2015); while they cannot replace experience, they do prepare students for future working experiences with real-world stakeholders in a group project (ibidem).

These group activities, conducted predominantly outside the classroom, have favoured a better relationship with peers in the group, and even with the other classmates. However, the work outside the classroom entailed an extra important effort, which students considered would be excessive if all the annual subjects had the same requirements. The students agreed that, if this were the case, all the subjects of the first year should reach an agreement to develop a common project, an event that students considered to be unlikely. Student commentaries emphasised two of the main challenges for effectively integrating SD in university curricula, namely overcrowded curricula and existing disciplinary boundaries (Holm et al., 2015; Sammalisto et al., 2015).

It should be noted that some groups carried out additional and time-consuming activities for their blog, which were not required in the subject programme, for example creating short videos focused on global issues, with special references to water. These initiatives started from the students' need to understand the global challenges in a more visual and straightforward way. It can be argued that this deepening on issues related to SD is related to a heightened interest in global challenges arisen within the subject.

What appears to be missing, in the opinion of the majority of the students involved in the focus group, is a final discussion at the end of the course with professors and classmates. This would have allowed an overall discussion on the issues studied during the course and favoured a deeper reflection on the decisions taken by the different groups on the dam construction. Through the methodology of the portfolio, each group had developed its own blog, and the different conclusions could be consulted online. Nonetheless, the students reiterated that the discussion would have facilitated the sharing and discussion of ideas and decisions.

"In fact, I also think that professors should do a closer follow-up of our work, right? So, after we turn in our conclusions, we should debate them in class among all the students and share all the conclusions".

"I think that you can look at it [the presentations and conclusions in the blogs of the other groups], but it would have been better to discuss it in class to know the opinions of each group.... I don't know, it is better in class".

It is important to note the considerations of the students on the 'social' role of the engineer. Their comments emphasise how the engineer's professional role is commonly associated with the world of the industrial production and the maximization of profit for private enterprises. Students recognise the social role of this professional profile and identify themselves professionally as bearers of change 
rather than only for profit. The social value of engineers is widely recognised in academic literature (Davidson et al., 2010; Karatzoglou, 2013) as well as by international institutions (UNESCO, 2010).

"I believe that society has a very selfish concept of the engineer, and we have to be the ones who see that we can help other people and not just work in a company for economic profit. It's thanks to projects like this one that we start to believe in ourselves, that yes—we can change things."

Consequently, they were requesting that higher education be less abstract and more centred on realworld problems. Contextually, they highlighted the need to be educated as 'persons', implicitly recognizing the presence of values in educational practices despite being primarily abstract (as linear algebra can be). This contrasts with most of the paradigms and educational models commonly used in engineering studies (Halbe et al., 2015).

“... I think that besides learning to do calculus, it is important to be trained as an engineer and also as a person. I think that contributes to providing a more critical vision... let's say... about everything I have, the global society and water, for example...”

Finally, students claim that, along with water topics, they are interested in other major SD issues, such as waste, pollution, and labour exploitation.

\subsection{First semi-structured interview}

In this section the first semi-structured interview conducted with the academic coordinator of the subject of linear algebra is presented and discussed. The interview was conducted in the professor's office at the end of the semester of the programme implementation and lasted approximately one hour.

The professor acknowledged the usefulness of the training process, and especially highlighted the benefits in terms of professional competencies. She remarks that, after identifying the potential topics to be integrated in the subject, the real challenge was how to embed these concepts into the subject. For this reason, she believed that the training process, especially the interchange of experiences with colleagues participating in the programme, were constructive and rewarding. On the one hand, she partially ascribed the difficulties encountered to the fact that linear algebra is a scientific discipline characterised by abstract structures that does not offer many examples to integrate sustainability related concepts. On the other hand, the professor stated that she believed SD concepts should be integrated into regular subjects at the very beginning of engineering studies, in order for students begin to actively reflect on such issues from the beginning, without having to postpone these reflections to future courses (either regular or specific for SD). This perspective confirms prior research on the incorporation of SD in universities curricula, specifically that incorporating SD concepts into regular courses contributes to raising student awareness on such principles and thereby 
increases their opportunities to integrate them into their professional life (Kamp, 2006; Lozano and Lozano, 2014).

The interviewee describes some activities conducted during the training programme in a particularly positive way. First, the use of a set of contextual case studies based on real SD projects, jointly developed by academics and members of non-governmental organizations (GDEE, 2015b), aimed at providing academic staff with specific materials to be used in the classroom. The usefulness of these cases is described specifically in terms of providing examples of 'what can be assessed and how to assess SD issues', although cases might deal with issues not directly related to the expertise of the professor. This confirms the lack of appropriate material as a problem to integrate SD (Peet et al., 2004), as well as the fact that the availability of practical teaching resources is valuable and useful for embedding SD into engineering subjects (Boni and Pérez-Foguet, 2008; Pérez-Foguet et al., 2005). Another issue emphasised as a relevant group exercise for professional competencies of academics was the joint creation of a general rubric to assess UPC transversal competence 'sustainability and social commitment', which stands apart but complements the regular subject's disciplinary assessment. Despite reporting the relevance of this activity in terms of training, however, the final result was described by the professor as not entirely applicable to the subject of linear algebra. Specifically, the assessment rubric that was developed was described as being overly complex and time consuming, especially considering that it should assess the transversal competence of a basic science subject.

The professor was highly satisfied with student commitment to SD issues presented in the subject. She reported that the vast majority of the students were engaged in developing reflections into their works and portfolios on water issues as SD challenge. Although some of the student contributions might be considered as too general or without sufficient depth, she emphasised that first year students are commonly struggling with some of the most demanding subjects of the course, some of which they often do not recognise as having any practical usefulness. In this particular teaching project, the perception of the coordinator was that students, in addition to gaining insight on SD topics, also understood the importance of abstract languages (such as mathematics) and recognised their potential for resolving real-world problems.

The preparation of the teaching project represented a considerable investment of time for the professor. The main difficulty to overcome was described as the process of identifying a complex problem that embedded SD, and that was mathematically resolvable with the level of student; at the same time, the solution should not be obvious, but rather stimulate the students' motivation to take up a challenge. In other words, the problem should not be resolved by simply applying a mathematical formula, but should remain open for different positions, fostering reasoning and discussion among students. Noticeably, the preparation of this educational project was a challenge primarily for the professor who, after dedicating a great deal of effort into this project, is currently working on a second 
one addressed for repeating students for the following semester. The considerable engagement of this professor highlights the fact that, although the engagement of academics with SD is commonly favoured by appropriate incentive structures at university level (Krizek et al., 2012; Stephens et al., 2008), often the efforts towards the integration of SD emerge from personal motivation and narratives, which outline a different and individual manner to engage with SD (Wood et al., 2016).

Different barriers hindering a broader integration of issues related to SD in university courses were highlighted during the interview. First of all, resistance to change by academics was mentioned, and specifically, resistance to: the integration of innovative topics in the curriculum, such as SD; to using the appropriate assessment methods, which involve the need to rethink the teaching routine of professors; to student assessment methods; to specific professional training. This represents a strong disincentive for potentially interested academics. Furthermore, the professor emphasised the lack of a clear and consistent message from the institution regarding SD; specifically, she claims that "sustainability should not remain only in the institutional statements" and that its integration should be actively fostered in the curriculum, even with top-down coercive strategies. The fact that a transversal competence specifically related to SD has been formally included in UPC curricula does not ensure its effective integration. Indeed, only a minority of academics at UPC are currently engaged or proficient with SD issues in teaching, and the institution provides limited incentives or professional training. This context discourages a global integration of SSC competence into the core engineering curricula and rather limits it to a number of disciplines/fields that are more relatable to the environmental aspects of SD, as can be appreciated in Table 1. This validates the extensive literature on the barriers for the integration of SD into the university system (Lozano, 2006; Lozano et al., 2013; Velazquez et al., 2006; Verhulst and Lambrechts, 2014). The professor was aware of the fact that her involvement could be a wasted effort if permanent structures of the university only recognise the importance of SD principles in communications and declarations but do not additionally provide active support for the integration of such principles into their different functions. It can be argued that the interviewee did not fully perceive the complexity of the process of institutionalisation of an innovation. In fact, as reported by Lozano (2006), coercive strategies "generates conflicts and the innovation is bound to lose strength with a change of authorities". Nonetheless, she acknowledged the fact that the integration of SD concepts into courses and curricula requires a concerted effort among different university stakeholders (Lozano-García et al., 2009).

Finally, the professor asserted that she will follow-up and further deepen the integration of SD issues, exploring potential new topics to be incorporated into the subject of linear algebra. Contextually, she reported that her involvement will not be limited to her teaching function, believing in the importance of promoting SD issue also at the institutional level, for example, by disseminating and discussing with colleagues the teaching innovation related to the integration of sustainability, with a particular focus on mathematics. Currently, her dissemination activities are not limited to the sphere of UPC; in 
fact, this case study was recently presented by the professor as a contribution for a national congress on 'University and Sustainable Development Goals' (Garcia-Planas and Taberna, 2017). Moreover, she claimed to be firmly convinced of the need to actively promote changes in engineering curricula to effectively include the transversal competence 'sustainability and social commitment', and stated that she will be personally engaged in this goal. As highlighted in other research focused on continuing education of academics (Barth and Rieckmann, 2012) this case study confirms that faculty professional development on SD has positive effects that go beyond teaching function, fostering transformative changes towards a sustainable university.

In conclusion, the approach employed to facilitate the integration of SD produced positive effects on faculty involved, reinforcing previous experience based on similar methods (Holmberg et al., 2012; Peet et al., 2004). Specifically, the case study analysed brought about positive effects not only for the professor who introduced SD into the courses but also, and most importantly, for the engineering students, who not only acquired subject-specific concepts but also developed important insight that allowed them to self-reflect about the engineering profession and the social benefits to which they could contribute at once finished their studies. It is especially important to highlight that students involved in these courses recognised the social utility for the promotion of SD not only in engineering per se but also in an otherwise abstract discipline such as linear algebra. Finally, the professor interviewed was highly positive and strongly motivated about the value of integrating SD, and was engaged in further promoting sustainability concepts in formal and informal university spheres.

\subsection{Second semi-structured interview}

The second semi-structured interview was conducted in the office of one of the authors, one year after the first interview, and lasted approximately one hour. After having briefly introduced the purpose of the interview and asked the professor to describe her current involvement with SD in her academic functions, the situation depicted by the interviewee, at one year into the professional training, was quite unexpected and jarring. At this point, the professor had been teaching Lineal Algebra for more than thirty years at UPC and had been the academic coordinator for linear algebra during the two years prior to introducing SD into her class (which was given in her third year as coordinator). However, before the start of her fourth year as coordinator, the professor was removed from her position as coordinator and released from her teaching duties (as a Spanish civil servant, she is still employed by the university). Note that the positive evaluations from the students discussed in the previous section referred to this professor's course in her third year as coordinator. These dire circumstances forced the authors to adapt the structure of the interview that had initially been planned to the actual situation of the professor, with more in-depth questions about some professional aspects that were not covered in the first interview. At the same time, the decision was made to leave more space to the interviewee to describe any significant aspects that could have led to the current situation. 
As a possible cause, the professor described significant resistance from her colleagues in the department, especially related to the introduction of a new pedagogical approach and student evaluation, which would have been expected to be followed also by the other professors teaching linear algebra. It is worth emphasising that the SSC competence was not previously included in the subject of Lineal Algebra. The decision to integrate the transversal competence had been approved by the board of the programme; nonetheless, this novelty might have dissatisfied a number of professors. Additionally, this reaction possibly overlapped with other internal dynamics related to the evaluation and promotion of the departmental teaching staff. For this reason, it is very difficult to identify if, and to what degree, the activities specifically fostered by the training action might have contributed to the current dismal situation of the professor. In the opinion of the professor, this resistance was not specifically directed against the integration of the principles of the SD per se (notably, SSC crosscutting competence is formally included in every engineering degree at UPC) but rather was a reaction to the modification/improvement of the "traditional" way of teaching mathematics. The interviewee emphasised that, for her colleagues at the department who are engaged in teaching, innovation processes do not represent a competitive advantage; on the contrary, it makes them feel insecure because their role as experts can be questioned. For this reason, it might be preferable for them to avoid initiative rather than to take advantage of it. The resistance, therefore, seems to be aimed first at protecting the "comfort zone” and self-confidence of the teaching staff (Cebrián et al., 2015; Lozano, 2006) and second, at preserving the formal and informal departmental power structures and mechanisms.

The professor stated that this unfavourable condition has not discouraged her, and that her interest in teaching innovation and SD has not diminished. On the contrary, she took advantage of the imposed “teaching break" to complete and publish a book of teaching materials aimed at integrating SD into linear algebra (García Planas et al., 2018). She is convinced that SD integration fosters students' interest for algebra and helps them to identify the importance of mathematical disciplines for global challenges. Given the current lack of opportunities at UPC to put into practice her teaching experience, she is planning to intensify research collaborations on teaching innovation with colleagues of other universities. Her interest and personal motivation for teaching innovation has progressively evolved from the traditional teaching of mathematical disciplines to the PBL approach and (recently) the integration of the SD principles. Her narration confirms that the incentives offered by UPC have been systematically used and have led to the achievement of her objectives. This is consistent with the scientific literature on sustainability champions (Hoover and Harder, 2015; Stephens et al., 2008; Wood et al., 2016).

After the second interview to the professor, one of the three national unions at UPC, which represents civil servants of public universities, brought the issue of the professor relieved of her teaching to public discussion, through the publication of a post entitled "A good CV wasted?" (CSIF, 2018). The 
post rhetorically asked whether the university board could allow that professors with a prestigious curriculum be relieved of their teaching, for political manoeuvres. The post links the complete curriculum vitae of the academic, as well as the teaching guide of the subject of Lineal Algebra of the last semester coordinated.

Several factors have made it extremely difficult for the authors to interview other parties involved in this matter, including the public outreach, the public scrutiny of the university board (which is currently deliberating on this matter) and the fact that the professor involved in this study is affiliated to a university union. However, by analysing publicly-available information (such as the curricula of the different programmes of study related to the subject) and by comparing the teaching guides of Lineal Algebra from the semester analysed in this study with the guides of following semesters, we have obtained some indications of a possible cause of the controversy. Specifically, it is notably that SSC transversal competences have not been included in the teaching guides of following semesters nor in the evaluation through the e-portfolio.

Thus, we conclude that the issue of teaching innovation appears to have been the trigger for this situation, even if the exact motivations are currently unclear. In any case, we would like to emphasise that this study shows that professional training and incentives can be useful for professors who are motivated and willing to accept teaching innovation. Notwithstanding, at the same time, other dynamics characterising the academic context can easily jeopardise the results achieved.

\section{Conclusions}

This research was aimed at assessing the effects of the integration of SD in regular subjects of basic engineering science, implemented in the first year of engineering studies. Specifically, the perception of the students involved and the academic coordinator of a subject of basic engineering science integrating SD were analysed. The analysis of this initiative allows emphasising the following conclusions.

First, CPD initiatives on SD have positive effects not only on students' knowledge and specific competencies related to sustainability, but also on their vision as future professionals of the engineering field, engaged with sustainability in its multiple dimensions. In fact, students appreciate learning about the potential applications in the real world of an abstract matter, such as linear algebra, and about potential social applications of this subject. Furthermore, the social role of the professional profile of an engineer is acknowledged, and students identify themselves professionally as "bearers of change”. 
Second, the integration of SD principles in regular courses of engineering is a complex process involving academics mostly with a strong disciplinary expertise. CPD approaches based on bottom-up approximations aimed at fostering personal opportunities of integration of sustainability principles, starting from personal expertise of academics, are effective approximations to train and engage faculty in SD. Nevertheless, these activities involve a large investment of time and effort for academics, specifically regarding abstract disciplines, such as those comprised in formal science. Individual coaching, as well as specific teaching materials and contextual case studies, can help faculty to embed SD in their subjects. Furthermore, group activities conducted with lecturers are effective to stimulate interest and sense of community among academics.

Third, CPD initiatives focused at integrating SD into teaching can have positive effect beyond teaching practices. Specifically, once academics are sufficiently involved and have acquired selfreliance on the effectiveness of their teaching, they can further engage in promoting SD in other functions and spheres of the university. These positive results can be reinforced by promoting appropriate incentives to the faculty. Nonetheless, specific university cultures and values, as well as barriers and resistance by academics to innovative processes, may contribute to frustrating the efforts of motivated professors.

Finally, in order to foster lasting academic engagement, permanent structures of universities should actively encourage and support the integration of SD principles into their different functions, by not only formally acknowledging SD commitment but also effectively implementing it throughout the system.

\section{Final remarks}

Part of the results of this study were incorporated in the doctoral thesis of Boris Lazzarini. The thesis was submitted on 30 September 2018, made public for the period announced according to the university's standard procedures, and defended in a public ceremony on 14 January 2019, at which it obtained a qualification of Excellent Cum Laude. On the date of acceptance of the article, no comments have been received that detract from the validity of the results presented in this article.

\section{Acknowledgements}

The authors would like to thank the colleagues and the students for their participation in this research. They would also thank the Barcelona City Council (Ref. 15S04656-001) and the Agencia de Gestió d'Ajuts Universitaris i de Recerca de la Generalitat de Catalunya - AGAUR (Ref. 2017 SGR 1496), which financed this initiative. Funding sources had no involvement in study design; in the collection, analysis and interpretation of data; in the writing of the report; and in the decision to submit the contribution. 


\section{References}

Absell, C.D., 2015. The Lexicon of Development: A Quantitative History of the Language of Development Studies. Iberoam. J. Dev. Stud. 4, 4-34.

Barth, M., Rieckmann, M., 2012. Academic staff development as a catalyst for curriculum change towards education for sustainable development: An output perspective. J. Clean. Prod. 26, 2836. doi:10.1016/j.jclepro.2011.12.011

Boni, A., Pérez-Foguet, A., 2008. Introducing development education in technical universities: successful experiences in Spain. Eur. J. Eng. Educ. 33, 343-354. doi:10.1080/03043790802088723

Boni, A., Pérez-Foguet, A., 2006. Propuestas pedagógicas para la introducción de la educación para el desarrollo en las enseñanzas científico-técnicas. Intermón Oxfam.

Brockhaus, S., Fawcett, S.E., Knemeyer, A.M., Fawcett, A.M., 2017. Motivations for environmental and social consciousness: Reevaluating the sustainability-based view. J. Clean. Prod. 143, 933947. doi:10.1016/j.jclepro.2016.12.027

Cebrián, G., Grace, M., Humphris, D., 2015. Academic staff engagement in education for sustainable development. J. Clean. Prod. 106, 1-16. doi:10.1016/j.jclepro.2014.12.010

Ceulemans, K., De Prins, M., 2010. Teacher’s manual and method for SD integration in curricula. J. Clean. Prod. 18, 645-651. doi:10.1016/j.jclepro.2009.09.014

Charmaz, K., 2006. Constructing Grounded Theory: A Practical Guide Through Qualitative Analysis, SAGE Publications. Sage Publications. doi:10.1017/CBO9781107415324.004

Chen, B., DeMara, R.F., Salehi, S., Hartshorne, R., 2018. Elevating Learner Achievement Using Formative Electronic Lab Assessments in the Engineering Laboratory: A Viable Alternative to Weekly Lab Reports. IEEE Trans. Educ. 61, 1-10. doi:10.1109/TE.2017.2706667

CSIF, 2018. ¿Un buen currículum desaprovechado? [WWW Document]. URL http://www.csifuniscatalunya.org/pdi_profes_reflexions_1.htm

Davidson, C.I., Hendrickson, C.T., Matthews, H.S., Bridges, M.W., Allen, D.T., Murphy, C.F., Allenby, B.R., Crittenden, J.C., Austin, S., 2010. Preparing future engineers for challenges of the 21st century: Sustainable engineering. J. Clean. Prod. 18, 698-701.

doi:10.1016/j.jclepro.2009.12.021

De Graaff, E., Kolmos, A., 2006. Management of change: implementation of problem-based and project-based learning in engineering. Sense Publishers.

EScGD, 2018. Case Studies to Integrate and Promote Global Issues in STEM Education. EScGD, Barcelona.

Garcia-Planas, M.I., Taberna, J., 2017. Integración de los Objetivos de Desarrollo Sostenible en la asignatura de Álgebra lineal impartida en la ETSEIB -UPC, mediante PBL, in: VII Congreso 
Universidad y Cooperación Al Desarrollo - La Universidad y Los Objetivos de Desarrollo Sostenible (29-31 March, 2017). Madrid.

García Planas, M.I., Taberna Torres, J., Rina García, N., 2018. Álgebra lineal en la educación para el desarrollo sostenible, Primera ed. ed. Iniciativa Digital Politècnica, Barcelona.

GDEE, 2015a. Global Dimension in Engineering Education [WWW Document]. URL http://gdee.eu/

GDEE, 2015b. Case studies for developing globally responsible engineers [WWW Document]. URL http://upcommons.upc.edu/handle/2117/88905

Halbe, J., Adamowski, J., Pahl-Wostl, C., 2015. The role of paradigms in engineering practice and education for sustainable development. J. Clean. Prod. 106, 272-282.

doi:10.1016/j.jclepro.2015.01.093

Holm, T., Sammalisto, K., Grindsted, T.S., Vuorisalo, T., 2015. Process framework for identifying sustainability aspects in university curricula and integrating education for sustainable development. J. Clean. Prod. 106, 164-174. doi:10.1016/j.jclepro.2015.04.059

Holmberg, J., Lundqvist, U., Svanström, M., Arehag, M., 2012. The university and transformation towards sustainability: The strategy used at Chalmers University of Technology. Int. J. Sustain. High. Educ. 13, 219-231. doi:10.1108/14676371211242544

Holmberg, J., Svanström, M., Peet, D.-J., Mulder, K., Ferrer-Balas, D., Segalàs, J., 2008. Embedding sustainability in higher education through interaction with lecturers: Case studies from three European technical universities. Eur. J. Eng. Educ. 33, 271-282. doi:10.1080/03043790802088491

Hoover, E., Harder, M.K., 2015. What lies beneath the surface? The hidden complexities of organizational change for sustainability in higher education. J. Clean. Prod. 106, 175-188. doi:10.1016/j.jclepro.2014.01.081

Kamp, L., 2006. Engineering education in sustainable development at Delft University of Technology. J. Clean. Prod. 14, 928-931. doi:10.1016/j.jclepro.2005.11.036

Karatzoglou, B., 2013. An in-depth literature review of the evolving roles and contributions of universities to Education for Sustainable Development. J. Clean. Prod. 49, 44-53. doi:10.1016/j.jclepro.2012.07.043

Krizek, K.J., Newport, D., White, J., Townsend, A.R., 2012. Higher education's sustainability imperative: how to practically respond? Int. J. Sustain. High. Educ. 13, 19-33. doi:10.1108/14676371211190281

Krueger, R.A., 2015. Focus groups: a practical guide for applied research. SAGE.

Lazzarini, B., Pérez-Foguet, A., 2018. Profiling research of the engineering academics who successfully promote education in Sustainable Human Development. J. Clean. Prod. 172, 42394253. doi:10.1016/J.JCLEPRO.2017.08.234 
Lazzarini, B., Pérez-Foguet, A., Boni, A., 2018. Key characteristics of academics promoting Sustainable Human Development within engineering studies. J. Clean. Prod. 188, 237-252. doi:10.1016/J.JCLEPRO.2018.03.270

Leal Filho, W., Raath, S., Lazzarini, B., Vargas, V.R., de Souza, L., Anholon, R., Quelhas, O.L.G., Haddad, R., Klavins, M., Orlovic, V.L., 2018. The role of transformation in learning and education for sustainability. J. Clean. Prod. 199, 286-295. doi:10.1016/j.jclepro.2018.07.017

Lehmann, M., Christensen, P., Du, X., Thrane, M., 2008. Problem-oriented and project-based learning (POPBL) as an innovative learning strategy for sustainable development in engineering education. Eur. J. Eng. Educ. 33, 283-295. doi:10.1080/03043790802088566

Lozano-García, F.J., Huisingh, D., Delgado-Fabián, M., 2009. An interconnected approach to incorporate sustainable development at Tecnológico de Monterrey. Int. J. Sustain. High. Educ. 10, 318-333. doi:10.1108/14676370910990675

Lozano, F.J., Lozano, R., 2014. Developing the curriculum for a new Bachelor's degree in Engineering for Sustainable Development. J. Clean. Prod. 64, 136-146. doi:10.1016/j.jclepro.2013.08.022

Lozano García, F.J., Gándara, G., Perrni, O., Manzano, M., Elia Hernández, D., Huisingh, D., Guillermo, F.J.L., Orietta, G., Mario, P., Dora, M., Hernández, E., Guillermo, F.J.L., Orietta, G., Mario, P., Dora, M., Hernández, E., 2008. Capacity building: a course on sustainable development to educate the educators. Int. J. Sustain. High. Educ. 9, 257-281. doi:10.1108/14676370810885880

Lozano, R., 2006. Incorporation and institutionalization of SD into universities: breaking through barriers to change. J. Clean. Prod. 14, 787-796. doi:10.1016/j.jclepro.2005.12.010

Lozano, R., Lukman, R., Lozano, F.J., Huisingh, D., Lambrechts, W., 2013. Declarations for sustainability in higher education: becoming better leaders, through addressing the university system. J. Clean. Prod. 48, 10-19. doi:10.1016/j.jclepro.2011.10.006

Mulder, K.F., Ferrer, D., Segalas Coral, J., Kordas, O., Nikiforovich, E., Pereverza, K., 2015. Motivating students and lecturers for education in sustainable development. Int. J. Sustain. High. Educ. 16, 385-401. doi:10.1108/IJSHE-03-2014-0033

Patton, M.Q., 2015. Qualitative Research \& Evaluation Methods Integrating Theory and Practice. Sage Publications.

Peet, D.J., Mulder, K.F., Bijma, A., 2004. Integrating SD into engineering courses at the Delft University of Technology: The individual interaction method. Int. J. Sustain. High. Educ. 5, 278-288. doi:10.1108/14676370410546420

Pérez-Foguet, A., Cruz López, Y., 2011. UPC’s institutional transformation towards sustainability, in: Higher Education in the World 4. Higher Education's Commitment to Sustainability: From Understanding to Action. Palgrave Macmillan Ltd., pp. 301-307.

Pérez-Foguet, A., Lazzarini, B., Giné, R., Velo, E., Boni, A., Sierra-Castañer, M., Zolezzi, G., Trimingham, R., 2018. Promoting sustainable human development in engineering: Assessment 
of online courses within continuing professional development strategies. J. Clean. Prod. 172, 4286-4302. doi:https://doi.org/10.1016/j.jclepro.2017.06.244

Pérez-Foguet, A., Oliete-Josa, S., Saz-Carranza, A., 2005. Development education and engineering: A framework for incorporating reality of developing countries into engineering studies. Int. J. Sustain. High. Educ. 6, 278-303. doi:10.1108/14676370510607241

Rose, G., Ryan, K., Desha, C., 2015. Implementing a holistic process for embedding sustainability: A case study in first year engineering, Monash University, Australia. J. Clean. Prod. 106, 229-238. doi:10.1016/j.jclepro.2015.02.066

Sammalisto, K., Sundström, A., Holm, T., 2015. Implementation of sustainability in universities as perceived by faculty and staff - a model from a Swedish university. J. Clean. Prod. 106, 45-54. doi:10.1016/j.jclepro.2014.10.015

Segalàs, J., Ferrer-Balas, D., Svanström, M., Lundqvist, U., Mulder, K.F., 2009. What has to be learnt for sustainability? A comparison of bachelor engineering education competences at three European universities. Sustain. Sci. 4, 17-27. doi:10.1007/s11625-009-0068-2

Sharma, B., Steward, B., Ong, S.K., Miguez, F.E., 2017. Evaluation of teaching approach and student learning in a multidisciplinary sustainable engineering course. J. Clean. Prod. 142, 1-9. doi:10.1016/j.jclepro.2016.10.046

Stephens, J.C., Hernandez, M.E., Román, M., Graham, A.C., Scholz, R.W., 2008. Higher education as a change agent for sustainability in different cultures and contexts. Int. J. Sustain. High. Educ. 9, 317-338. doi:10.1108/14676370810885916

Svanström, M., Palme, U., Wedel, M.K., Carlson, O., Nyström, T., Edén, M., 2012. Embedding of ESD in Engineering Education -Experiences from Chalmers University of Technology. Int. J. Sustain. High. Educ. 13, 279-292. doi:10.1108/14676371211242580

UNDP, 2011. Human Development Report 2011. Sustainability and Equity: A Better Future for All. Sustain. Equity A Better Futur. All (November 2, 2011). UNDP-HDRO Hum. Dev. Reports 176.

UNESCO, 2010. Engineering: Issues, Challenges and Opportunities for Development. UNESCO Publishing.

Velazquez, L., Munguia, N., Platt, A., Taddei, J., 2006. Sustainable university: what can be the matter? J. Clean. Prod. 14, 810-819. doi:10.1016/j.jclepro.2005.12.008

Verhulst, E., Lambrechts, W., 2014. Fostering the incorporation of sustainable development in higher education. Lessons learned from a change management perspective. J. Clean. Prod. 106, 189204. doi:10.1016/j.jclepro.2014.09.049

von Blottnitz, H., Case, J.M., Fraser, D.M., 2015. Sustainable development at the core of undergraduate engineering curriculum reform: a new introductory course in chemical engineering. J. Clean. Prod. 106, 300-307. doi:10.1016/j.jclepro.2015.01.063

Watson, M.K., Lozano, R., Noyes, C., Rodgers, M., 2013. Assessing curricula contribution to 
sustainability more holistically: Experiences from the integration of curricula assessment and students' perceptions at the Georgia Institute of Technology. J. Clean. Prod. 61, 106-116. doi:10.1016/j.jclepro.2013.09.010

Wood, B.E., Cornforth, S., Beals, F., Taylor, M., Tallon, R., 2016. Sustainability champions? Academic identities and sustainability curricula in higher education. Int. J. Sustain. High. Educ. 17, 342-360. doi:10.1108/IJSHE-12-2014-0171 